\title{
Low-temperature Oxidation of 1,3,5-trimethylbenzene over Copper Oxide Film Catalyst Using a New Catalytic Jet-Stirred Reactor
}

\author{
Guanfu Pan, ${ }^{1,2,3}$ Achraf El Kasmi ${ }^{1}$ and Zhenyu Tian ${ }^{1,2, *}$
}

The catalytic oxidation of 1,3,5-trimethylbenzene (T135MB), which is a simple model of aromatic hydrocarbons, was investigated with a newly designed catalytic jet-stirred reactor (CJSR) equipped with gas chromatography and FTIR at low temperature. Thin film of pure CuO was synthesized at $325^{\circ} \mathrm{C}$ using one-step pulsed-spray evaporation chemical vapor deposition. To better understand the interplay between properties and catalytic performances, the obtained catalysts were characterized in terms of crystalline phase, morphology and surface composition. The catalytic performance based on light-off curves revealed that $\mathrm{CuO}$ deposited on mesh of stainless steel presented a very high activity against the complete oxidation of $\mathrm{T} 135 \mathrm{MB}$ at $330{ }^{\circ} \mathrm{C}$. The induced catalytic effect is attributed to the open porosity, small grain size, abundance of surface adsorbed oxygen of $\mathrm{CuO}$, and the long residence time provided by the newly designed CJSR. Moreover, a possible mechanism was proposed for the complete oxidation of T135MB in CJSR. Accordingly, the combined diagnostic method involving the novel designed CJSR and efficient analysis devices is expected to assist in further understanding of the abatement of complex gaseous pollutants with avoiding high toxic byproducts paving the way for clean combustion applications.

Keywords: Catalytic Jet-Stirred Reactor; T135MB; Catalytic oxidation; Thin film catalysts; CuO

Received 16 August 2018, Accepted 3 December 2018

DOI: $10.30919 / \mathrm{esee} 8 \mathrm{c} 185$

\section{Introduction}

In recent years, aromatic compounds have been recognized as air pollutants issued from transportation activities and fossil fuel combustion processes. $^{1,2}$ 1,3,5-Trimethylbenzene (T135MB), a model of aromatic hydrocarbons that can be released into the air as unburned fuel since it is a representative component of real jet fuels, ${ }^{3}$ or emitted by evaporative emissions and automobile tailpipe exhaust, was considered as a harmful pollutant in the atmosphere. ${ }^{4,5}$ Its conversion can play, in the atmosphere, a significant role in the increase of tropospheric ozone and in the formation of secondary organic aerosol, in addition to its toxicity to humans. ${ }^{6,7}$ In attempts to reduce T135MB in the emissions, catalytic oxidation is one of the most efficient technologies owing to its advantage of carrying out reaction at low-temperature. ${ }^{8,9}$ However, the catalytic efficiency depends greatly on the reactor design because of the variation in the residence time and the homogeneity of the gas phase. ${ }^{10}$

Although jet-stirred reactor (JSR) has been widely involved in the studies the kinetics of homogeneous combustion due to its long residence time, ${ }^{10}$ the heterogeneous reactions using catalytic JSR (CJSR) has been scarcely studied. Thus, with regard to harmful effects of $\mathrm{T} 135 \mathrm{MB}$, the study of the complete catalytic oxidation of T135MB using newly designed CJSR will be of interest. Moreover, diagnostic of the formed species within the CJSR using different analysis devices, to

${ }^{1}$ Institute of Engineering Thermophysics, Chinese Academy of Sciences, Beijing 100190, China

${ }^{2}$ University of Chinese Academy of Sciences, Beijing 100049, China

${ }^{3}$ Present address: Energy Conservation Corporation Ltd. of China Coal

Research Institute, Beijing 100013, China

*E-mail: tianzhenyu@iet.cn overcome the incapability of detecting the unstable species as well as overlapped species' peaks, is a good issue to be considered for better understanding the complete catalytic oxidation of T135MB.

The catalytic oxidation has been widely performed using precious metals due to their highly catalytic activity at low temperature. ${ }^{8,911-13}$ However, considering the limited resources, high price and tendency to poisoning of such noble metals, and regarding the advantages provided by transition metal oxides, such as competitive activity at without dash, high thermal stability and low cost, the latter have attracted much attention in developing active catalysts. ${ }^{14,15} \mathrm{CuO}$ is one of the most active transition metal oxide catalysts, which is abundantly available and non-toxic and has been used in several applications. ${ }^{16-18}$ Several methods have been performed to synthesize $\mathrm{CuO}^{19-22}$ However, a mixture of copper metal and oxides was obtained in most of these studies, which prevents the kinetic understanding of their application. Thus, the synthesis of pure $\mathrm{CuO}$ is desired for CJSR applications. Compared to other techniques such as hydrothermal, ${ }^{19}$ sputtering, ${ }^{20}$ chelating method $^{23}$ and pulsed laser deposition, ${ }^{24}$ pulsed-spray evaporation chemical vapor deposition (PSE-CVD) method is a direct, inexpensive and facile technique for the synthesis of continuous thin film oxides with high purity. Recently, it has been successfully performed to synthesize a series of active transition metal oxides for low-temperature catalytic oxidation. ${ }^{25-27}$ It is therefore important to synthesize film catalysts with PSE-CVD for catalytic oxidation of T135MB using CJSR.

In this work, $\mathrm{CuO}$ film catalysts have been synthesized using onestep PSE-CVD method. The abatement study of T135MB as unburned fuel has been investigated using catalytic oxidation technology. An attempt was made to reveal the interplay between the morphology, surface composition and structure of the $\mathrm{CuO}$ films with its catalytic 
performance. A new diagnostic setup based on CJSR-GC/FTIR was adopted for complete catalytic oxidation of T135MB at low temperature. A possible surface mechanism was proposed for complete catalytic oxidation of $\mathrm{T} 135 \mathrm{MB}$ over the $\mathrm{CuO}$ film catalysts, which could pave the way for other catalytic applications using CJSR.

\section{Experimental}

\subsection{Synthesis}

The preparation of $\mathrm{CuO}$ films was performed using PSE-CVD method. ${ }^{28} \mathrm{Cu}(\mathrm{acac})_{2}$ precursor dissolved in an alcohol solvent (ethanol) was delivered as feedstock to the evaporation chamber of CVD reactor kept at $200{ }^{\circ} \mathrm{C}$, then transported to the deposition chamber with flow rates of $\mathrm{N}_{2} / \mathrm{O}_{2}=0.5 / 1.0$ slm under a pressure of $4 \mathrm{kPa}$. Substrates of glass and stainless steel were used here that heated up to $325^{\circ} \mathrm{C}$. The details of the experimental conditions for $\mathrm{CuO}$ synthesis is available in the Supplemental Materials (SM).

\subsection{Characterization}

The crystalline phases of the synthesized films were identified by XRD analysis using a Bruker D8 Focus equipped with a $\mathrm{Cu} \mathrm{K} \alpha$ radiation source, within a $2 \theta$ range of $10-90^{\circ}$. The surface morphology of the obtained films was examined by SEM (S-4800 Hitachi) with a resolution of $1.5 \mathrm{~nm}$. The surface chemical composition of the films was determined by the XPS (ESCALAB 250Xi).

\subsection{Diagnostic of catalytic oxidation}

The investigation of catalytic performance of the $\mathrm{CuO}$ film catalysts was performed in a newly designed CJSR system for deep oxidation of T135MB, as shown in Fig. S1 (see SM). The CJSR is made of fused silica in attempt to minimize catalytic reactions and consists of a sphere with $5 \mathrm{~cm}$ inner diameter $\left(\sim 104 \mathrm{~cm}^{3}\right)$ and 4 nozzles in the center of reactor with $0.3 \mathrm{~mm}$ inner diameter. The reactor is designed to be opened and closed based on the retention of the JSR four nozzle design. In the selection of the middle connection mode, the use of ground glass interface with a snap connection was performed to ensure air tightness and taking into account the quartz glass material. In order to have sufficient mixing space inside the reactor, the reactor sphere is elongated from the middle, thus a $20 \mathrm{~mm}$ long columnar structure was employed between the two hemispheres. This part is a double-layer nested structure. Grinding glass was used to ensure sealing. After testing, it can be secured that fully meet the requirements of the experimental tightness. During experiments, heating band was used to preheat the inlet and outlet gases at $200{ }^{\circ} \mathrm{C}$ to avoid condensation.

The full-scale setup used to perform the catalytic oxidation of T135MB is shown in Fig. 1. During experiments, the gasification of T135MB was achieved by bubbling method; the temperature of heating of $\mathrm{T} 135 \mathrm{MB}$ liquid was calculated according to the partial vapor pressure needed in this experiment. Argon gas was passed through the T135MB liquid as a carrier gas during bubbling and controlled by mass

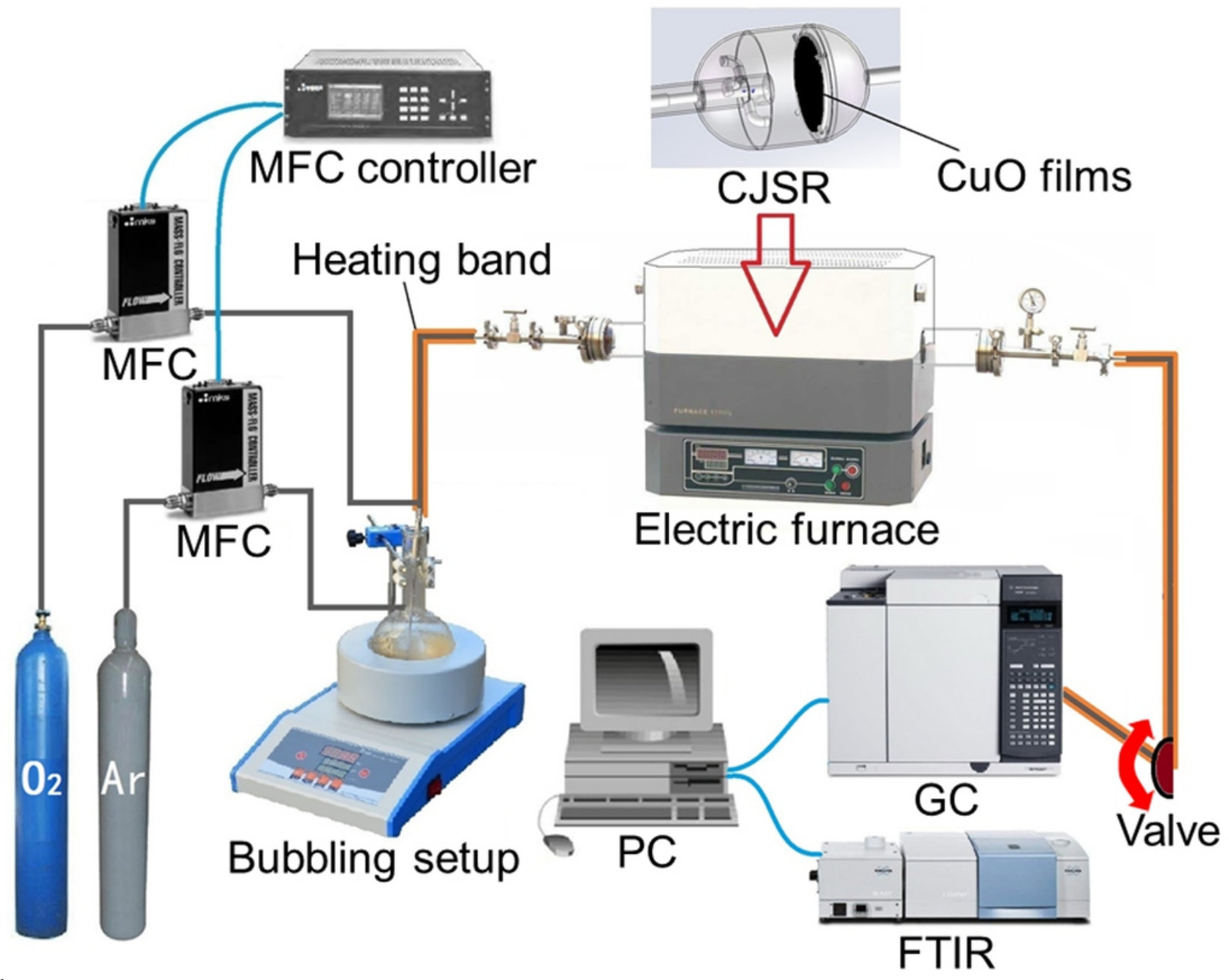

Fig. 1 Setup of T135MB catalytic oxidized by $\mathrm{CuO}$ films. 
flow controller. $\mathrm{CuO}$ film catalyst coated on stainless steel mesh was inserted in CJSR and placed at the uniform temperature zone of electric furnace, as shown in Fig. 1. Moreover, a non-coated mesh was used in some tests as a reference and named as NCM; while in the case of ER, no mesh or catalyst was inserted in the CJSR reactor. The temperature of $\mathrm{CuO}$ catalyst was measured during the reaction by using a $\mathrm{K}$ thermocouple. A gas mixture, consisted of $1 \% \mathrm{~T} 135 \mathrm{MB}$ and $30 \% \mathrm{O}_{2}$ diluted in Ar, was introduced into CJSR with a flow rate of $30 \mathrm{ml} / \mathrm{min}$ corresponding to the gas hourly space velocity (GHSV) of 51,724 ml $\mathrm{g}_{\text {cat }}^{-1} \mathrm{~h}^{-1}$, which calculated by referring to the mass of the $\mathrm{CuO}$ layer. The residence time of the flow inside the CJSR is calculated to be in the range of 1.12-7.84 seconds. The outlet gases were analyzed using both Gas Chromatograph (Agilent 7890B) and FTIR (Bruker VERTEX 70) equipped with gaseous cell for qualitative and quantitative analysis. The estimated experimental errors of mole fractions are within $\pm 5 \%$. As the reaction of $\mathrm{T} 135 \mathrm{MB}$ was a complete oxidation, the $\mathrm{T} 135 \mathrm{MB}$ was converted completely into $\mathrm{CO}_{2}$, and the production of $\mathrm{CO}_{2}$ was evaluated directly from its peak either in GC or FTIR, as function of temperature, based on the following expression:

$$
\mathrm{Co}_{2}(\%)=\left[\mathrm{CO}_{2}\right]_{\text {formed }} /[\text { Carbon }]_{\text {inlet }} * 100 \%
$$

\section{Results and discussion}

\subsection{Structure}

The crystalline phases of the films deposited on glass substrate were identified as shown in Fig. 2. The diffracted peaks are observed at $2 \theta$ of $32.508^{\circ}, 35.543^{\circ}, 38.708^{\circ}, 48.716^{\circ}, 61.524^{\circ}, 66.220^{\circ}, 68.123^{\circ}$, corresponding to (110), (11-1), (111), (20-2), (11-3), (31-1) and (220) planes, which match well with those of $\mathrm{CuO}$ structure (JCPDS No. 48-
1548). No impurity of phases' peaks were detected, which indicates a high purity of the $\mathrm{CuO}$ deposited films. In this work, the characteristic peak for the calculation was located at $35.543^{\circ}$. The crystallite size was estimated to be about $51 \pm 1 \mathrm{~nm}$ by applying the Scherrer equation, which is smaller than the crystallite size of $\mathrm{CuO}$ reported in the literature. ${ }^{29}$ Also as reported in our previous work, the catalytic activity can be improved by decreasing the particle size. ${ }^{25}$ The small grain size can contribute positively on active sites dispersion that are involved in the increase of the catalytic performance. ${ }^{30}$ Accordingly, the small grain

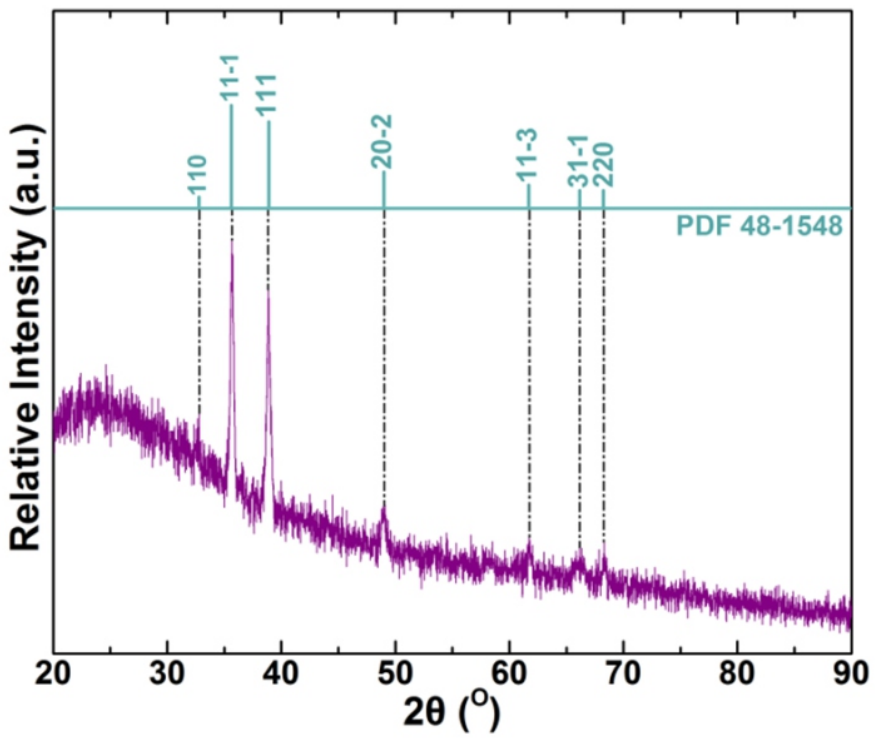

Fig. 2 XRD pattern of the $\mathrm{CuO}$ film sample deposited on glass.
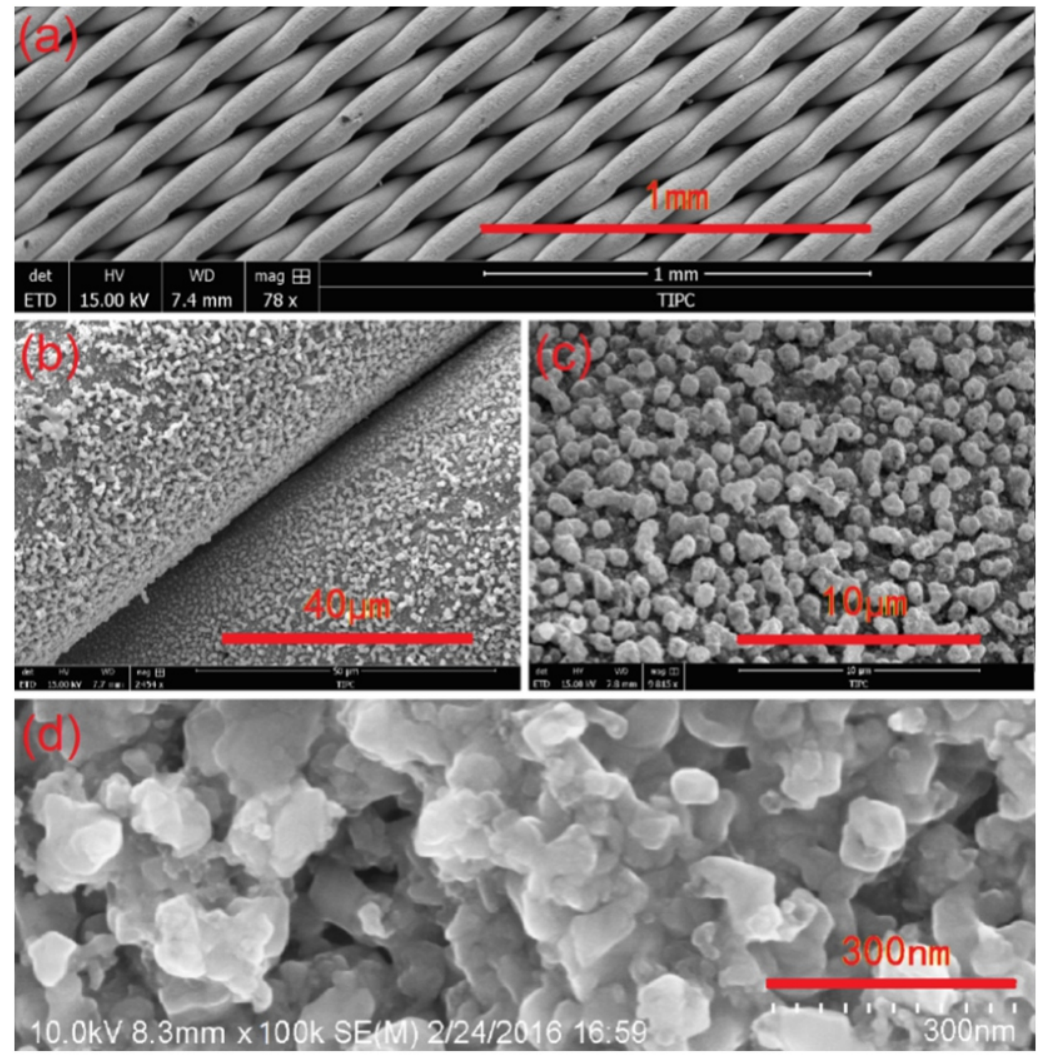

Fig. 3 SEM images of $\mathrm{CuO}$ films deposited on grid mesh of stainless steel at different magnifications. 
size obtained in this work might be helpful for the catalytic oxidation.

\subsection{Morphology}

To obtain the surface morphology of the formed films on stainless steel grid mesh, SEM analysis was performed. Fig. 3 shows the representative SEM images of the obtained films at different magnifications of $1 \mu \mathrm{mm}, 40 \mu \mathrm{m}, 10 \mu \mathrm{m}$ and $300 \mathrm{~nm}$. The lowmagnification SEM images indicate that the film presents a good homogeneity, uniformity and continuous structure. The high-magnification micrograph of the formed films (Fig. 3d) exhibits that estimated average grain size is $\sim 50 \mathrm{~nm}$, which matches with the grain size determined from XRD data. Comparing to the synthesis of catalytically active copper oxide by Tian et al. $^{29}$, the arrangement of $\mathrm{CuO}$ surface presents much open and porous structure. Therefore, the formed films with small grain sizes and open porosity are expected to offer high surface area with providing predisposed space holding more oxygen, which will be then beneficial to the catalytic oxidation performance of aromatic compounds.

\subsection{Chemical composition}

The high-resolution XPS of $\mathrm{O} 1 \mathrm{~s}$, as presented in Fig. 4a, shows the deconvolution into two main components in the range of binding energy (BE) $525.00-538.00 \mathrm{eV}$. The located peak at $529.65 \mathrm{eV}$ is assigned to the species of the lattice oxygen $\mathrm{O}^{2-}\left(\mathrm{O}_{\mathrm{Lat}}\right)$, while the peak at higher $\mathrm{BE}(531.65 \mathrm{eV})$ is characteristic to the presence of adsorbed species such as, hydroxyl species $\mathrm{OH}$, organic oxides or defects in the structure as well as adsorbed oxygen $\left(\mathrm{O}_{\mathrm{Ads}}\right)$ species. ${ }^{31,32}$ In addition to the main chemical elements, the carbon content detected at the surface of the prepared samples, commonly comes from the decomposition of the precursor during deposition and/or ambient air, is quite negligible in the bulk (after $28.5 \mathrm{~nm}$ etching), as shown in Fig. 5). The atomic ratio of $\mathrm{Cu}$ and $\mathrm{O}$ at the surface of the films after etching, is around 1:1. Accordingly, this result is in line with XRD results that confirms the obtained crystalline structure of $\mathrm{CuO}$.

To confirm the purity of the $\mathrm{CuO}$ structure, auger spectrum analysis was involved (see Fig. 3b). To exclude the influence of overlap from the characteristic peaks of $\mathrm{Cu}^{2+}$ and $\mathrm{Cu}^{+}$in $\mathrm{Cu} 2 \mathrm{p}$ spectrum, Auger spectrum of $\mathrm{CuO}$ sample (Fig. $4 \mathrm{~b}$ ) was used to demonstrate the purity of the $\mathrm{CuO}$ structure by nonlinear fitting method. The obvious peak in the $\mathrm{Cu}$ LM2 spectrum located at $921.15 \mathrm{eV}$ that coincides with the standard auger spectrum of $\mathrm{CuO}$, which confirms here the high purity of $\mathrm{CuO}$ structure.

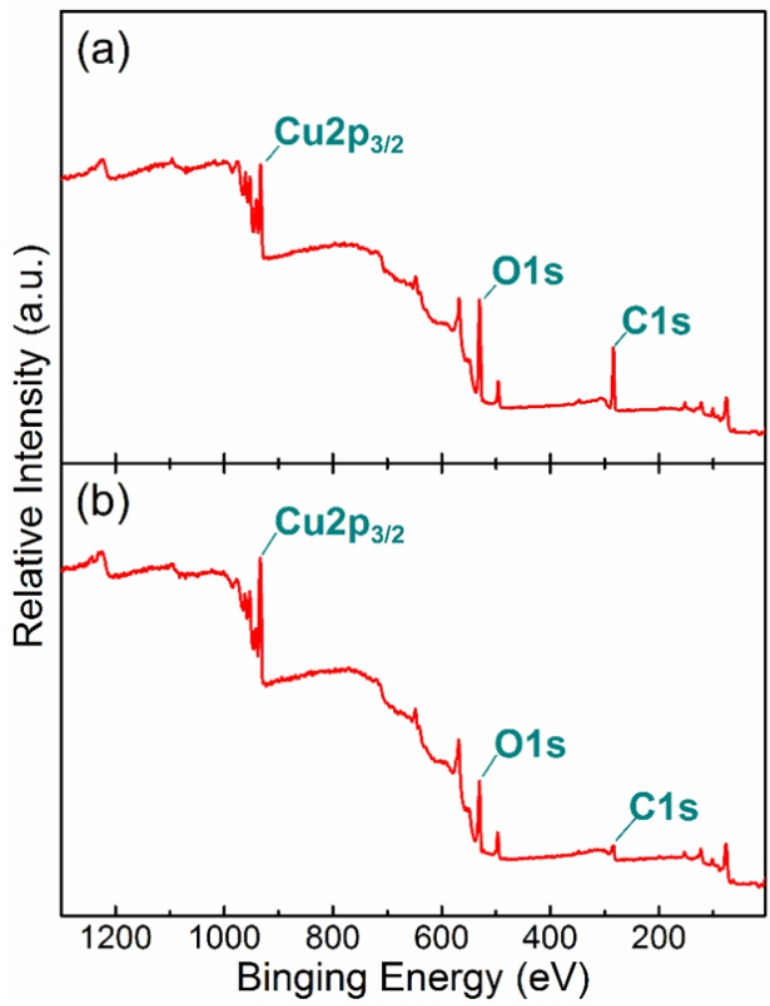

Fig. 5 Entire XPS spectra of $\mathrm{CuO}$ thin films (a) before and (b) after $28.5 \mathrm{~nm}$ etching.
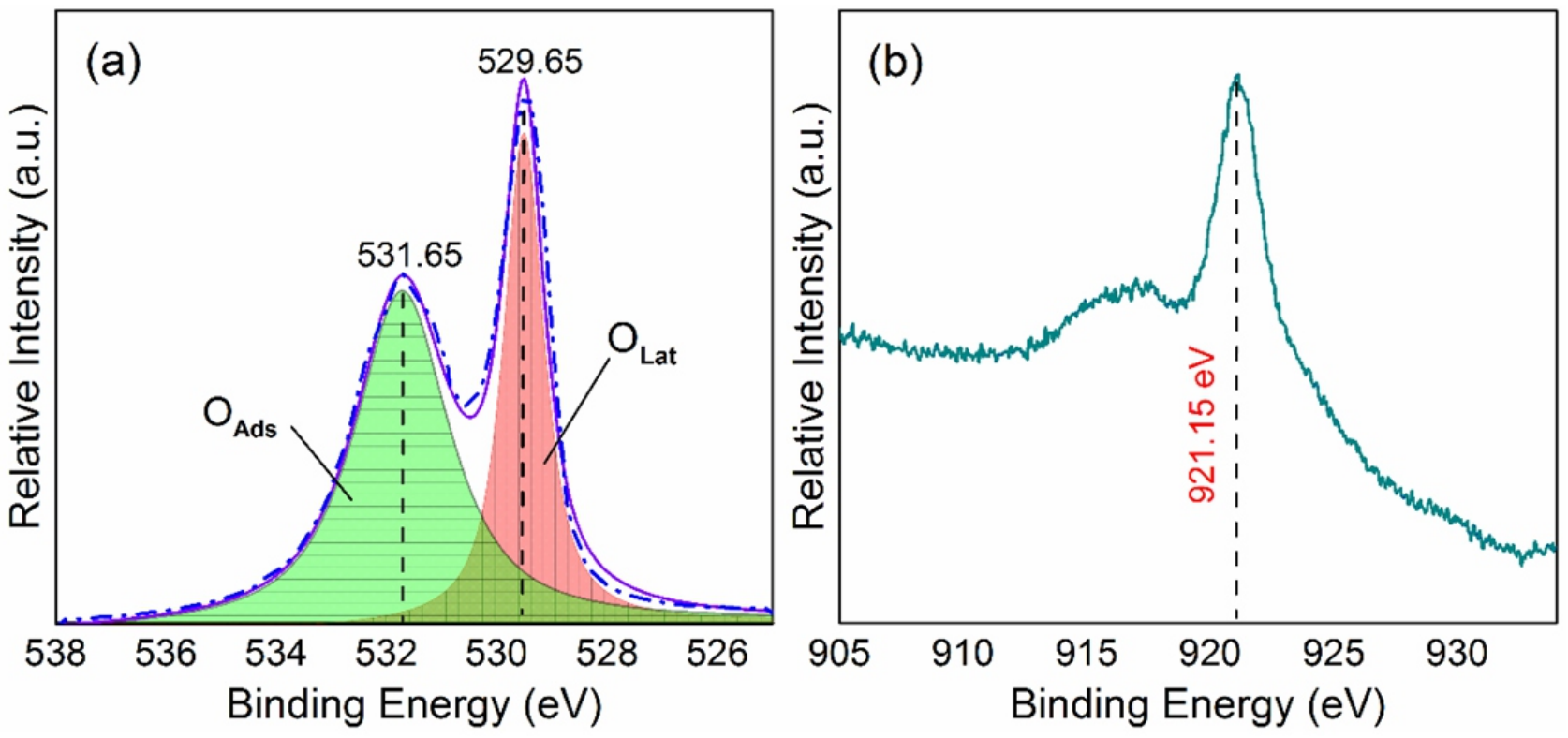

Fig. 4 XPS spectra of (a) $\mathrm{O} 1 \mathrm{~s}$ and (b) $\mathrm{Cu} \mathrm{LM} 2$ of $\mathrm{CuO}$ films. 

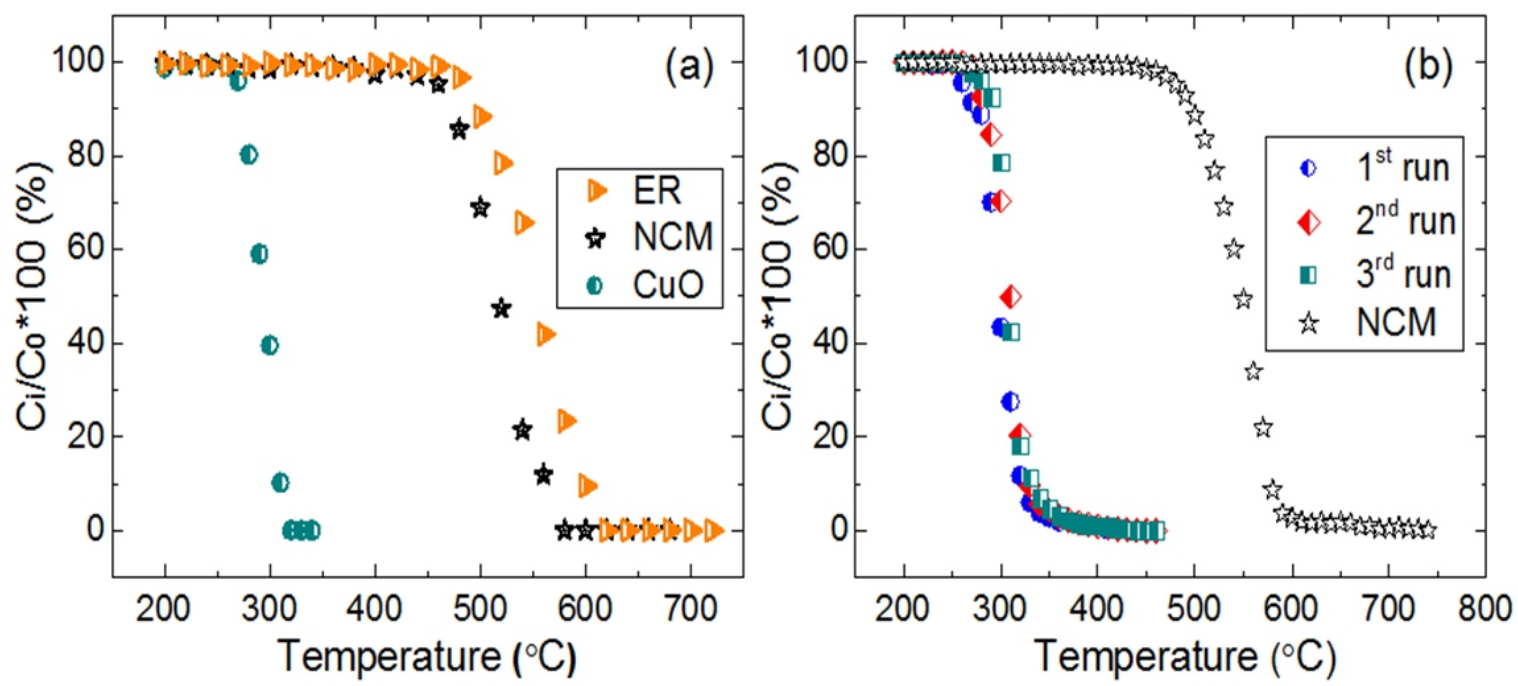

Fig. 6 Curves of T135MB consumption during its conversion measured by (a) GC and (b) FTIR.

\subsection{Catalytic performance}

A newly designed CJSR was used for the catalytic oxidation of T135MB over supported $\mathrm{CuO}$ thin film catalyst. To evaluate the support effect, experiments were carried out over non-coated (NCM) of stainless steel as well as using empty reactor (ER) under similar conditions. Fig. 6 presents the comparison of the temperature dependent conversion ratio of T135MB of ER, NCM and $\mathrm{CuO}$ coated mesh using both GC and FTIR. The results showed that NCM can shift only slightly the total oxidation temperature towards lower values when comparing to that of ER, whereas CuO-coated mesh permits significantly to shift the total oxidation temperatures towards much lower values. The onset of $\mathrm{T} 135 \mathrm{MB}$ conversion over $\mathrm{CuO}$-coated mesh occurs almost at $270{ }^{\circ} \mathrm{C}$ and the total conversion takes place at $330{ }^{\circ} \mathrm{C}$, while for NCM and ER the total conversion is achieved at $\sim 580$ and $\sim 610{ }^{\circ} \mathrm{C}$, respectively. Moreover, the reproducibility of the obtained results was evaluated by repeating the catalytic reaction over $\mathrm{CuO}$ catalyst for several times and very good results were obtained without a significant temperature change, as shown in Fig. 6 b.

Table 1 presents the conversion temperatures of $\mathrm{T}_{90}, \mathrm{~T}_{50}$ and $\mathrm{T}_{10}$ that correspond to $90 \%, 50 \%$ and $10 \%$ conversion of $\mathrm{T} 135 \mathrm{MB}$, respectively. Comparing to $\mathrm{NCM}$ and $\mathrm{ER}$, it is obvious that $\mathrm{CuO}$ film catalyst is very active for T135MB oxidation at low-temperature using CJSR. Furthermore, the apparent activation energies $\left(\mathrm{E}_{\text {appa }}\right)$ of $\mathrm{T} 135 \mathrm{MB}$ oxidation in the case of $\mathrm{ER}, \mathrm{NCM}$ and $\mathrm{CuO}$ were determined according to Arrhenius expression using the data till up $15 \%$ conversion. The $\mathrm{E}_{\text {appa }}$ values of T135MB oxidation found to be $(141 \pm 1),(138 \pm 1)$ and $(69 \pm 1)$ $\mathrm{kJ} \mathrm{mol}^{-1}$ for $\mathrm{ER}, \mathrm{NCM}$ and $\mathrm{CuO}$-coated mesh, respectively. The observed difference in $\mathrm{E}_{\text {appa }}$ results illustrates that $\mathrm{CuO}$ catalyst can significantly reduce the activation barrier of $\mathrm{T} 135 \mathrm{MB}$ oxidation and make the oxidation of $\mathrm{T} 135 \mathrm{MB}$ occur at lower temperature and thus results in shifting the light-off curves to low temperatures. As a consequence, the lower $\mathrm{E}_{\text {appa }}$ presents the lower conversion $\mathrm{T} 135 \mathrm{MB}$ temperature and very good catalytic activity.

Fig. 7 shows the local reaction rate of T135MB conversion as function of temperature, which can give detailed information about the catalytic behavior of the reaction rate. Below $270{ }^{\circ} \mathrm{C}$, the reaction rate was insensitive to the temperature, reflecting that no reaction was occurred at that stage. From $270{ }^{\circ} \mathrm{C}$, corresponding to the onset conversion temperature of $\mathrm{T} 135 \mathrm{MB}$ over $\mathrm{CuO}$, the reaction rate increased with the increase of temperature. This increase in reaction rate is in line with the previous observed enhancement in catalytic activity when increasing temperature of reaction, which confirms that temperature is very sensitive in the reaction and has a significant effect on the catalytic performance. Once the temperature achieved $\sim 330{ }^{\circ} \mathrm{C}$, the reaction rate became stable and no more sensitive to the temperature that reflects the achievement of conversion limitation temperature of T135MB using $\mathrm{CuO}$ catalyst within CJSR, which is perfectly in accordance with the temperature of complete catalytic oxidation of T135MB.

The diagnostic of the CJSR outlet gas at different temperatures using $\mathrm{GC}$ for $\mathrm{ER}, \mathrm{NCM}$ and $\mathrm{CuO}$ showed the intermediate species formed during the reaction. Once the NCM was used in the reaction (Fig. 8), the formed intermediates species' amounts were slightly reduced and their formation temperatures were shifted comparing to that

Table 1 Characteristic conversion temperatures of T135MB catalytic oxidation.

\begin{tabular}{cccc}
\hline Temperature & $\mathrm{CuO}$ & NCM & ER \\
\hline $\mathrm{T}_{10}\left({ }^{\circ} \mathrm{C}\right)$ & 280 & 480 & 500 \\
$\mathrm{~T}_{50}\left({ }^{\circ} \mathrm{C}\right)$ & 300 & 520 & 540 \\
$\mathrm{~T}_{90}\left({ }^{\circ} \mathrm{C}\right)$ & 320 & 560 & 600 \\
\hline
\end{tabular}




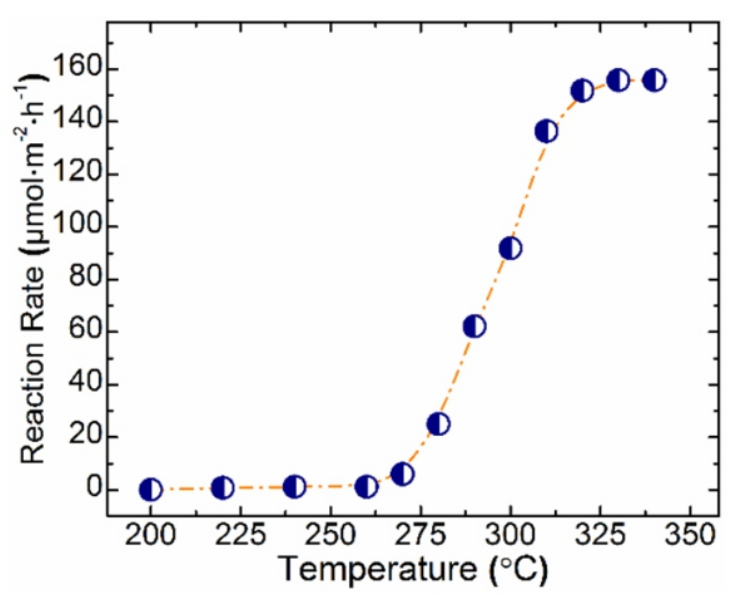

Fig. 7 Reaction rate of $\mathrm{T} 135 \mathrm{MB}$ catalytic oxidation by $\mathrm{CuO}$ at different temperatures.

observed for ER (Fig. 9), which reflects that the reaction pathway has been somewhat changed after inserting a NCM catalyst in the reaction.

Furthermore, the use of $\mathrm{CuO}$ as very active catalyst for T135MB oxidation makes the detection of the intermediates not so easy, which may be due to their small amounts produced during the reaction and also to the fast conversion of $\mathrm{T} 135 \mathrm{MB}$ over $\mathrm{CuO}$ catalyst. Thus, the reaction mechanism of $\mathrm{T} 135 \mathrm{MB}$ over $\mathrm{CuO}$ can be proposed according to occurred reactions over NCM (Eqs. 1-22). The main possible pathways were presented in Fig. 10. During the reaction process, the abundant available active sites on $\mathrm{CuO}$ surface can accelerate the adsorption of $\mathrm{O}_{2}$ and $\mathrm{T} 135 \mathrm{MB}$ on surface catalyst. Owing to the adsorbed oxygen species, such as $\mathrm{O}^{-}$or $\mathrm{O}_{2}^{-}$formed by the adsorption and decomposition of $\mathrm{O}_{2}$ molecule at the surface, the energy barrier of T135MB decomposition was significantly reduced. Taking into account the main intermediate species detected during the catalytic oxidation process are m-xylene, toluene, benzene, 1,3-butadiene, propenal, propyne and ethanol, the catalytic conversion of T135MB is discussed here. Firstly, T135MB was decomposed to m-xylene by losing one methyl radical, then to toluene and benzene by further losing a methyl radical in each step. In parallel, the formed benzene continued to decompose to 1,3-butadiene through the ring cleavage reaction with temperature increasing. Then, the decomposition of 1,3-butadiene that was previously formed at the same temperature of $\mathrm{m}$-xylene, led to form small molecules, such as propenal and ethanal. In addition, at

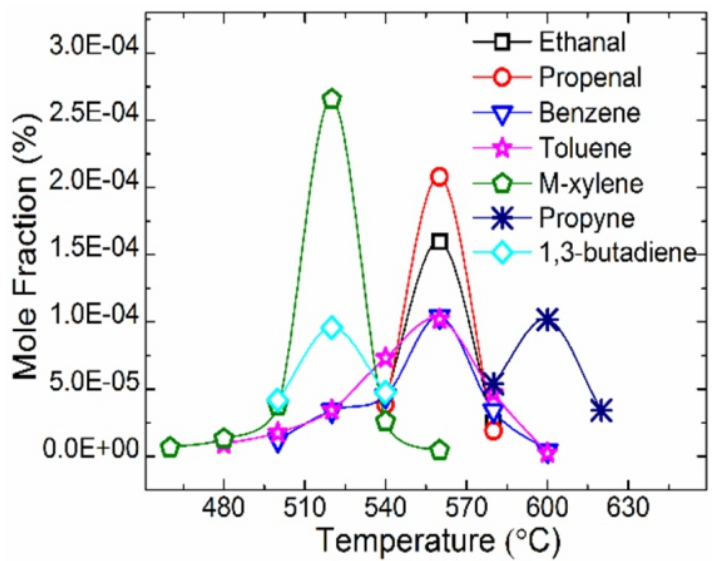

Fig. 8 Intermediates species detected by GC during the T135MB catalytic oxidation over NCM. much higher temperature, propyne was the only detected intermediate specie, which indicates the latter intermediates were converted into propyne. Furthermore, the small molecules continued to decompose into $\mathrm{CO}_{2}$ and water confirming the complete conversion of T135MB over $\mathrm{CuO}$ catalyst using CJSR.

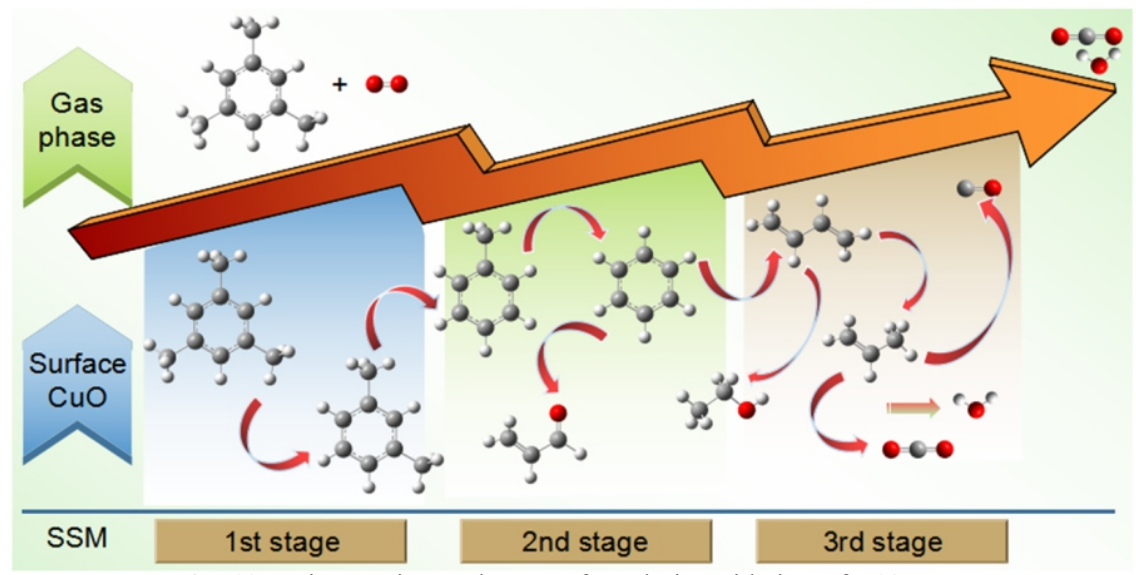

Fig. 10 Main reaction pathways of catalytic oxidation of T135MB. 


$$
\begin{aligned}
& \mathrm{O}_{2}(\mathrm{~g})+\mathrm{e}^{-} \longrightarrow \mathrm{O}_{2}{ }^{-} \text {(ads) } \\
& \mathrm{O}_{2}^{-} \text {(ads) }+\mathrm{e}^{-} \longrightarrow 2 \mathrm{O}^{-} \text {(ads) } \\
& \text { TMB135(g) } \rightarrow \text { TMB135(ads) } \\
& \text { TMB135(ads) }+\mathrm{O}^{-} \text {(ads) } \longrightarrow \text { d13mboj(ads) }+\mathrm{H}(\text { ads }) \\
& \mathrm{TMB} 135 \text { (ads) }+\mathrm{O}^{-} \text {(ads) } \longrightarrow \mathrm{d} 35 \mathrm{mb} \mathrm{ch}_{2} \text { (ads) }+\mathrm{OH}(\text { ads }) \\
& \mathrm{TMB} 135 \text { (ads) }+\mathrm{H}(\text { ads }) \longrightarrow \mathrm{m}-\mathrm{C}_{8} \mathrm{H}_{10} \text { (ads) }+\mathrm{CH}_{3} \text { (ads) } \\
& \mathrm{m}-\mathrm{C}_{8} \mathrm{H}_{10} \text { (ads) }+\mathrm{H} \text { (ads) } \longrightarrow \mathrm{C}_{6} \mathrm{H}_{5} \mathrm{CH}_{3} \text { (ads) }+\mathrm{CH}_{3} \text { (ads) } \\
& \mathrm{C}_{6} \mathrm{H}_{5} \mathrm{CH}_{3} \text { (ads) }+\mathrm{H}(\text { ads }) \longrightarrow \mathrm{C}_{6} \mathrm{H}_{6}(\text { ads })+\mathrm{CH}_{3} \text { (ads) } \\
& \mathrm{C}_{6} \mathrm{H}_{5} \mathrm{CH}_{3} \text { (ads) }+\mathrm{H}(\text { ads }) \longrightarrow \mathrm{C}_{4} \mathrm{H}_{5}(\text { ads })+\mathrm{pC}_{3} \mathrm{H}_{4} \text { (ads) } \\
& \mathrm{C}_{6} \mathrm{H}_{5} \mathrm{CH}_{3} \text { (ads) } \longrightarrow \mathrm{C}_{5} \mathrm{H}_{5} \text { (ads) }+\mathrm{C}_{2} \mathrm{H}_{3} \text { (ads) } \\
& \mathrm{C}_{4} \mathrm{H}_{5}(\mathrm{ads})+\mathrm{H}(\mathrm{ads}) \longrightarrow 1,3-\mathrm{C}_{4} \mathrm{H}_{6}(\mathrm{ads}) \\
& \mathrm{C}_{5} \mathrm{H}_{5} \text { (ads) }+\mathrm{OH}(\text { ads }) \longrightarrow 1,3-\mathrm{C}_{4} \mathrm{H}_{6} \text { (ads) }+\mathrm{CO} \text { (ads) } \\
& \mathrm{TMB} 135 \text { (ads) }+\mathrm{CO}(\text { ads }) \longrightarrow \mathrm{CHO}(\text { ads })+\mathrm{d} 35 \mathrm{mblch}_{2} \text { (ads) } \\
& \mathrm{CH}_{3} \text { (ads) }+\mathrm{CHO}(\text { ads }) \longrightarrow \mathrm{CH}_{3} \mathrm{CHO}(\text { ads }) \\
& \mathrm{C}_{2} \mathrm{H}_{3} \text { (ads) }+\mathrm{CHO}(\text { ads }) \longrightarrow \mathrm{C}_{2} \mathrm{H}_{3} \mathrm{CHO}(\text { ads }) \\
& \mathrm{CH}_{3} \mathrm{CHO}(\mathrm{ads}) \longrightarrow \mathrm{CH}_{3} \mathrm{CHO}(\mathrm{g}) \\
& \mathrm{C}_{2} \mathrm{H}_{3} \mathrm{CHO}(\text { ads }) \longrightarrow \mathrm{C}_{2} \mathrm{H}_{3} \mathrm{CHO}(\mathrm{g}) \\
& \mathrm{C}_{6} \mathrm{H}_{6} \text { (ads) } \longrightarrow \mathrm{C}_{6} \mathrm{H}_{6}(\mathrm{~g}) \\
& \mathrm{C}_{6} \mathrm{H}_{5} \mathrm{CH}_{3} \text { (ads) } \rightarrow \mathrm{C}_{6} \mathrm{H}_{5} \mathrm{CH}_{3}(\mathrm{~g}) \\
& \mathrm{m}-\mathrm{C}_{8} \mathrm{H}_{10} \text { (ads) } \rightarrow \text { m- } \mathrm{C}_{8} \mathrm{H}_{10}(\mathrm{~g}) \\
& \mathrm{pC}_{3} \mathrm{H}_{4} \text { (ads) } \rightarrow \mathrm{pC}_{3} \mathrm{H}_{4}(\mathrm{~g}) \\
& 1,3-\mathrm{C}_{4} \mathrm{H}_{6}(\mathrm{ads}) \longrightarrow 1,3-\mathrm{C}_{4} \mathrm{H}_{6}(\mathrm{~g})
\end{aligned}
$$

In addition, the analysis accuracy of carbon atoms during the catalytic oxidation of $\mathrm{T} 135 \mathrm{MB}$ can verify clearly whether the intermediate species are presented either with very low amounts that could not be easily detected during the reaction or with losing some intermediate species during the reaction. So, the effective number of carbon atoms was performed (Fig. 11) as an indicative for the analysis accuracy data for the catalytic oxidation of T135MB with using NCM and $\mathrm{CuO}$-coated mesh. Here, the effective number of carbon atoms was determined by calculating the carbon atom number of all products during the catalytic oxidation. The results revealed that the carbon balance for both $\mathrm{CuO}$ and $\mathrm{NCM}$ is around 9 and almost stable during the reaction, which means that the intermediates were detected accurately. Hence, it can be concluded that the experimental detection accuracy in the present work was performed with high accuracy.

Fig. 9 presents the production of $\mathrm{CO}_{2}$ during the complete catalytic oxidation of $\mathrm{T} 135 \mathrm{MB}$ over $\mathrm{NCM}$ and $\mathrm{CuO}$ catalysts. The production of $\mathrm{CO}_{2}$ over $\mathrm{CuO}$ catalyst was commenced at $270{ }^{\circ} \mathrm{C}$ that corresponds to the starting temperature of $\mathrm{T} 135 \mathrm{MB}$ conversion. Also, the temperature of saturated $\mathrm{CO}_{2}$ production corresponds to that of total $\mathrm{T} 135 \mathrm{MB}$ conversion. From that, it implies that the conversion of T135MB over $\mathrm{CuO}$ catalyst is a fast process that can lead rapidly to form $\mathrm{CO}_{2}$, which can explain the detection of $\mathrm{CO}_{2}$ only during the catalytic reaction over $\mathrm{CuO}$. In addition, it should be noted that no $\mathrm{CO}$ was detected during the conversion of $\mathrm{T} 135 \mathrm{MB}$ over $\mathrm{CuO}$ that confirms the high activity of $\mathrm{CuO}$ catalyst towards $\mathrm{CO}_{2}$, while for NCM a small amount of $\mathrm{CO}$ was observed.

The catalytic oxidation of aromatic hydrocarbons over catalysts based transition metal oxide is commonly accepted that follows the MvK mechanism. ${ }^{33}$ In accordance to XPS results that exhibited a great amount of adsorbed oxygen at the $\mathrm{CuO}$ surface catalyst (Fig. 4a). The catalytic oxidation of $\mathrm{T} 135 \mathrm{MB}$ over $\mathrm{CuO}$ catalyst is assumed to involve alternate oxidation and reduction of the oxides, with formation of vacancies of surface oxygen and their replenishment by the adsorption and dissociation of gaseous oxygen. ${ }^{34,35}$ Also, the nano-sized grain of $\mathrm{CuO}$ catalyst is important for reinforcing the catalytic performance. ${ }^{25}$ Consequently, the combination of applying $\mathrm{CuO}$ catalyst with these good properties, with using CJSR could provide very good catalytic performance in terms of activity and could further pave the way for other catalytic reactions at low temperature. Furthermore, owing to the long residence time of CJSR, the latter could be much suitable for catalytic kinetic study at low temperature.

\section{Conclusion}

A newly designed catalytic jet-stirred reactor equipped with FTIR and GC was used for the diagnostics of T135MB catalytic oxidation. Thin films of pure $\mathrm{CuO}$ catalysts, synthesized by PSE-CVD technique, exhibited cubic nano-sized crystallite and high amount of surface adsorbed oxygen. The complete catalytic oxidation of T135MB using CJSR revealed that $\mathrm{CuO}$ is a very active catalyst and the oxidation process using $\mathrm{CuO}$ catalyst is much faster than those with $\mathrm{NCM}$ and ER. The contribution of the $\mathrm{O}_{\mathrm{Ads}}$ abundance at the catalyst surface with

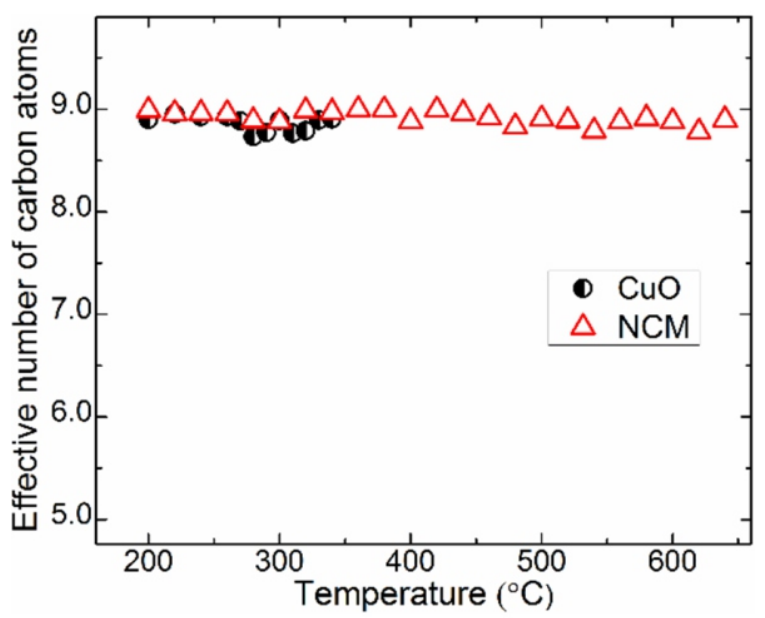

Fig. 11 Effective number of carbon atoms during T135MB conversion.

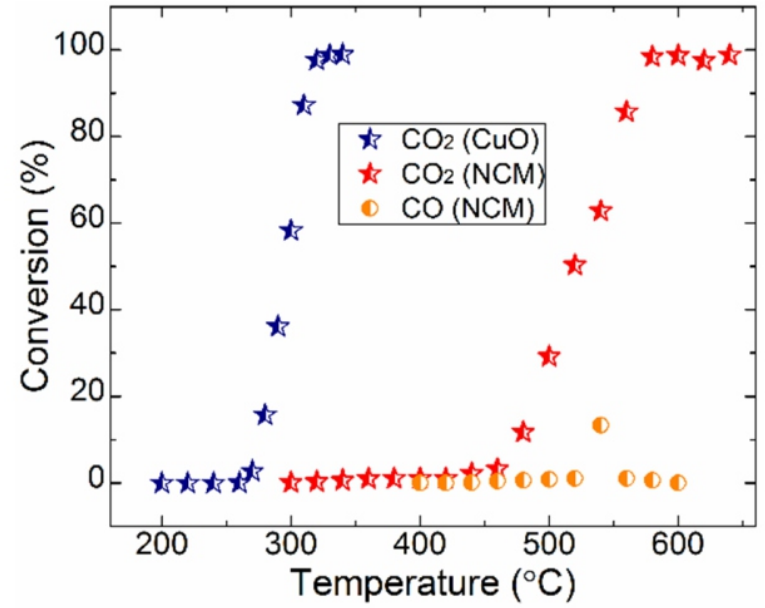

Fig. $12 \mathrm{CO}_{2}$ and $\mathrm{CO}$ production during catalytic oxidation of $\mathrm{T} 135 \mathrm{MB}$ over $\mathrm{CuO}$ and NCM. 
nano-crystallite and porous texture, in the catalytic performance of $\mathrm{CuO}$ using CJSR towards conversion of T135MB revealed a significant reduce in $\mathrm{E}_{\text {appa }}$ to $68.99 \mathrm{~kJ} \mathrm{~mol}^{-1}$. A possible mechanism of complete catalytic oxidation of $\mathrm{T} 135 \mathrm{MB}$ into $\mathrm{CO}_{2}$ using $\mathrm{CuO}$ catalyst was comprehensively discussed. The effective number of carbon atoms was performed to verify the analysis accuracy that revealed a high accuracy from the obtained results. The combination of the newly designed catalytic jet-stirred reactor with GC/FTIR is a useful diagnostic technique for kinetics of catalytic oxidation.

\section{Acknowledgement}

The authors thank the Ministry of Science and Technology of China (2017YFA0402800), Natural Science Foundation of China (No 51476168, 91541102) and Recruitment Program of Global Youth Experts for financial support. Dr. El Kasmi would kindly thank the support of Chinese Academy of Sciences for senior international scientists in the framework of PIFI program.

\section{References}

1. Z. Guo, B. Liu, Q. Zhang, W. Deng, Y. Wang and Y. Yang, Chem. Soc. Rev, 2014, 43, 3480-3524.

2. C. Du, S. Lu, Q. Wang, A. G. Buekens, M. Ni and D. P. Debecker, Chem. Eng. J., 2018, 334, 519-544.

3. T. Malewicki, S. Gudiyella and K. Brezinsky, Combust. Flame, 2013, 160, 17-30.

4. D. E. C. Mazzeo, T. C. C. Fernandes and M. A. Marin-Morales, Chemosphere, 2011, 85, 13-18.

5. S. M. Correa, G. Arbilla, M. R. C. Marques and K. M. P. G. Oliveira, Atmospheric Pollut. Res., 2012, 3, 163-169.

6. A. Metzger, J. Dommen, K. Gaeggeler, J. Duplissy, A. S. H. Prevot, J. Kleffmann, Y. Elshorbany, A. Wisthaler and U. Baltensperger, Atmospheric Chem. Phys. Discuss., 2008, 8, 11567-11607.

7. M. Huang, Y. Lin, X. Huang, X. Liu, X. Guo, C. Hu, W. Zhao, X. Gu, L. Fang and W. Zhang, Atmospheric Pollut. Res., 2015, 6, 209-219.

8. H. Huang, Y. Xu, Q. Feng and D. Y. C. Leung, Catal. Sci. Technol., 2015, 5, 2649-2669

9. Z. Zhang, Z. Jiang and W. Shangguan, Catal. Today, 2016, 264, 270-278.

10. O. Herbinet and G. Dayma, in Cleaner Combustion, Springer, London, 2013, pp. $183-210$.

11. C. Wang, C. Zhang, W. Hua, Y. Guo, G. Lu, S. Gil and A. Giroir-Fendler, Chem. Eng. J., 2017, 315, 392-402.
12. A. Wittstock, V. Zielasek, J. Biener, C. M. Friend and M. Bäumer, Science, 2010, 327, 319-322.

13. M. Wang, L. Zhang, W. Huang, T. Xiu, C. Zhuang and J. Shi, Chem. Eng. J., 2017, 320, 667-676

14. W. B. Li, J. X. Wang and H. Gong, Catal. Today, 2009, 148, 81-87.

15. N. Tien Thao and L. T. Kim Huyen, Chem. Eng. J., 2015, 279, 840-850.

16. Z. Jin, C. Liu, K. Qi and X. Cui, Sci. Rep., 2017, 7, srep39695.

17. L. Wang, H. Gong, C. Wang, D. Wang, K. Tang and Y. Qian, Nanoscale, 2012, 4, 6850-6855

18. N. Zhou, M. Yuan, D. Li and D. Yang, Nano, 2017, 12, 1750035.

19. T. Jiang, Y. Wang, D. Meng, X. Wu, J. Wang and J. Chen, Appl. Surf. Sci., 2014, 311, 602-608

20. J. K. Feng, H. Xia, M. O. Lai and L. Lu, Mater. Res. Bull., 2011, 46, 424 427.

21. Y. F. Lim, C. S. Chua, C. J. J. Lee and D. Chi, Phys. Chem. Chem. Phys., 2014, 16, 25928-25934.

22. J. Liu and D. Xue, Adv. Mater, 2008, 20, 2622-2627.

23. J. S. Yang, W. Y. Jung, W. K. Lee, K.- T. Lim, M. S. Lee and S.-S. Hong, $J$. Nanosci. Nanotechnol., 2011, 11, 1542-1546.

24. W. Seiler, E. Millon, J. Perrière, R. Benzerga and C. Boulmer-Leborgne, $J$. Cryst. Growth, 2009, 311, 3352-3358.

25. A. El Kasmi, Z. Y. Tian, H. Vieker, A. Beyer and T. Chafik, Appl. Catal. B Environ., 2016, 186, 10-18.

26. Z. Y. Tian, P. Mountapmbeme Kouotou, A. El Kasmi, P. H. Tchoua Ngamou, K. Kohse-Höinghaus, H. Vieker, A. Beyer and A. Gölzhäuser, Proc Combust. Inst., 2015, 35, 2207-2214.

27. Z. Y. Tian, P. Mountapmbeme Kouotou, N. Bahlawane and P. H. Tchoua Ngamou, J. Phys. Chem. C, 2013, 117, 6218-6224.

28. N. P. H. Tchoua, A. El Kasmi, T. Weiss, H. Vieker, A. Beyer, V. Zielasek, K. Kohse-Höinghaus and M. Bäumer, Z. Für Phys. Chem., 2015, 229, $1887-$ 1905.

29. Z. Y. Tian, H. J. Herrenbrück, P. Mountapmbeme Kouotou, H. Vieker, A. Beyer, A. Gölzhäuser and K. Kohse-Höinghaus, Surf. Coat. Technol., 2013, 230, 33-38.

30. K. Qadir, S. H. Joo, B. S. Mun, D. R. Butcher, J. R. Renzas, F. Aksoy, Z. Liu, G. A. Somorjai and J. Y. Park, Nano Lett., 2012, 12, 5761-5768.

31. M. C. Biesinger, L. W. M. Lau, A. R. Gerson and R. S. C. Smart, Appl. Surf. Sci., 2010, 257, 887-898.

32. A. Jablonski and C. J. Powell, National Institute of Standards and Technology, 2011

33. C. Doornkamp and V. Ponec, J. Mol. Catal. Chem., 2000, 162, 19-32.

34. H. Bao, X. Chen, J. Fang, Z. Jiang and W. Huang, Catal. Lett., 2008, 125, $160-167$.

35. E. Aneggi, J. Llorca, M. Boaro and A. Trovarelli, J. Catal., 2005, 234, 88-95. 